\title{
Mujeres jóvenes en el sistema de justicia juvenil
}

\author{
Young women in the juvenile justice system \\ Rosario Pozo Gordaliza \\ Universitat de les Illes Balears \\ rosario.pozo@uib.es
}

Recibido: 12/03/2012

Revisado: 07/09/2012

Aceptado: 02/01/2013

Disponible on line: 16/04/2013

\begin{abstract}
Resumen
El presente artículo recoge los resultados más significativos de una investigación empírica sobre trayectorias de vida de mujeres jóvenes en justicia juvenil. El análisis efectuado considera los factores, contextos y procesos más relevantes. Para facilitar su comprensión al lector/a, el texto se divide en dos apartados fundamentales; de la exclusión y victimización como estado a la vulnerabilidad como proceso de las jóvenes que delinquen y que terminan cumpliendo una medida de internamiento en la comunidad andaluza.
\end{abstract}

Palabras clave: delincuencia juvenil femenina, justicia juvenil, trayectorias de vida.

\begin{abstract}
This article describes the most significant results of empirical research on the life trajectories of young women in juvenile justice. The analysis considers the most relevant factors, contexts and processes. To facilitate the reader's understanding, the text is divided into two main sections, of exclusion and victimization as a state of vulnerability as a process of young women who offend and who end up serving a custodial sentence in Andalusia.
\end{abstract}

Keywords: female juvenile delinquency, juvenile justice, life trajectories.

Referencia normalizada: Pozo Gordaliza, R. (2013): «Mujeres jóvenes en el sistema de justicia juvenil». Cuadernos de Trabajo Social, 26(1): 181-191.

Sumario: Introducción. 1. Interés científico de la investigación. 2. Coordenadas de la investigación. 3. Algunos resultados de la investigación. 4. Discusiones finales. 5. Referencias bibliográficas.

\section{Introducción}

Este artículo está consagrado a un fenómeno invisible, a la ausencia y presencia de mujeres jóvenes en la escena institucional de la justicia juvenil, y al significado de esa ausencia y presencia. El objetivo central de esta investigación era comprender, analizar y describir los factores, los contextos y los procesos sociales por los cuales una joven llegaba a infringir la ley y a obtener una medida de internamiento en un centro de reforma juvenil. A partir de la experiencia vital de las jóvenes, se pretendió, en primer lugar, captar el sentido y el significado de cómo influye la socialización de género en la comisión de delitos y, en segundo lugar, conocer el porqué y el cómo muchas mujeres jóvenes comienzan a entrar en el circuito de la delincuencia, ahondando especialmente en los contextos en los que se producía. A través de una metodología eminentemente cualitativa, el presente estudio explora en profundidad las vidas, las percepciones, las emociones y las actuaciones, y ahonda en los factores, los procesos y los contextos sociales de las mujeres y niñas que rompen con la ley y a quienes se les aplica la sanción más dura, la de internamiento en un centro de reforma de menores, donde se aplican las medidas o los regímenes de cerrado, semiabierto y abierto, entre otras.

\section{Interés científico de la investigación}

Según Heidensohn (1985), Brown (1989) y Canteras (1999), las mujeres delincuentes han sido obviadas hasta hace más de veinte años, cuando comienzan a ser consideradas en la formulación de teorías generales. Algunas estu- 
diosas como Christine Alder y Anne Worrall, Girls violence. Myths and realities (2004) han coincidido en señalar que existen muchos libros que hablan sobre jóvenes y delincuencia, también textos sobre mujeres y delitos, pero casi nunca mencionan a las jóvenes. En cualquier caso la escasez o inexistencia de trabajos tanto de corte cuantitativo como cualitativo en materia de delincuencia juvenil femenina ${ }^{1}$, por lo que parece ser una obviedad que las chicas han sido largamente excluidas de los estudios científicos sobre delincuencia; según Meda Chesney-Lind (1980), no han suscitado debate alguno durante mucho tiempo. Por lo tanto, es como si éstas no existiesen.

El interés científico y profesional de la presente investigación está motivado precisamente por la exclusión cuasi permanente de las chicas jóvenes de la teoría y la investigación en materia de delincuencia juvenil. En el caso concreto de España, ésta se encuentra inmersa en un gran letargo, situación de negligencia en la que, en numerosas ocasiones, los datos de las jóvenes se pierden entre los trabajos sobre delincuencia masculina, que casi siempre toman como referencia los discursos de los varones que pasan por la justicia juvenil. Por todo ello, merece al menos una reflexión seria las cuestiones del cómo y el porqué se dan situaciones de delincuencia juvenil femenina, ya que en esta materia, los datos se pierden en las estadísticas.

De tal manera que conocemos bien poco del proceso de criminalización de estas jóvenes, sus vidas, los factores, el papel que la etnicidad juega en todo ello, los contextos y los procesos, además de las experiencias en torno a la medida de institucionalización y, asimismo, también conocemos poco sobre cómo las representan los diversos «sistemas de control» de justicia juvenil. Si nos fijamos en las últi- mas estadísticas del Instituto Nacional de Estadística (INE), nos daremos cuenta de la situación tan precaria de datos en torno a este objeto de estudio. La carencia de información es cuantitativa y cualitativa. El escaso número de delincuentes femeninas o demasiado pocas para que cuenten (too few too count) inmersas en el sistema de justicia juvenil, además es uno de los argumentos más utilizados a la hora de justificar este déficit de información e investigación. Pero lo cierto es que siguen siendo «el problema, que no es problema». Por encima de todo eso, son el pequeño grupo de las grandes olvidadas, the forgotten few.

\section{Coordenadas de la investigación}

El trabajo empírico se realizó en la comunidad andaluza y se tomaron como referencias fundamentales de análisis las historias de vida y las entrevistas sociodemográficas, aunque, para obtener una mayor validez y complementariedad en la información, se llevó a cabo una triangulación de métodos consistente en el análisis de ficheros, y la observación dentro de la institución de reforma juvenil femenina. Para el análisis de [44 ficheros], se seleccionaron tres provincias (y sus respectivos juzgados) con las mayores tasas de delincuencia en Andalucía. En la parte de la estancia en el centro, se llevaron a cabo: la observación etnográfica durante un mes de casi convivencia con las jóvenes y las 16 entrevistas sociobiográficas (Véase anexo 1). Esta última parte se realizó en el único centro de reforma juvenil femenino, donde ingresan las jóvenes que han cometido delitos en la franja de edad entre catorce años y menos de dieciocho, y que pueden permanecer en el centro hasta los veintiún años de edad $^{2}$ con medidas de institucionalización de todas las provincias andaluzas con las modalidades de abierto, semiabierto o cerrado o en

\footnotetext{
1 Sería A. Campbell, en su libro Girls Delinquents (1981), quien avisaría de los casi inexistentes trabajos etnográficos acerca de la delincuencia en la mujer, pese a ser más común de lo que se pensaba y de lo que demostraban las estadísticas oficiales.

2 En nuestro vigente Código Penal aprobado por Ley Orgánica 10/1995, de 23 de noviembre, la mayoría de edad penal quedó fijada en los dieciocho años de edad, si bien, en la Ley Orgánica 5/2000, de 12 de enero, reguladora de la Responsabilidad Penal de los Menores, se contempló la posibilidad de aplicar sus disposiciones a los mayores de dieciocho y menores de veintiún años cuando concurrieran las circunstancias previstas en el artículo 4 de la citada ley. Por tanto, las disposiciones de esta ley van a ser aplicables a los mayores de catorce y menores de dieciocho años presuntamente responsables de la comisión de infracciones penales, en tanto que a los menores de catorce años se les aplicarán las normas sobre protección de menores desarrolladas en el Código Civil y la Ley Orgánica 1/1996, de 15 de enero, de Protección Jurídica del Menor.
} 
centros psiquiátricos de la región. Finalmente, todo ello se ha complementado con estudios e investigaciones en torno a las jóvenes institucionalizadas o la delincuencia juvenil femenina. Se ha considerado en todo el proceso de investigación la clase socioeconómico (cultural) y la etnicidad.

\section{Algunos de los resultados de la investigación}

En los barrios y en las familias donde se concentran altas desventajas socioeconómicas y culturales, incluida la victimización, hay pocos recursos para proteger a las jóvenes y evitar que éstas se envuelvan en peligrosas actividades y proliferan estrategias alternativas a la legalidad. Por todo ello, es necesario mirar a las jóvenes desde la diferente proyección de roles de género, entrelazados con los de clase, cultura y etnia, y sus particulares controles formales e informales, así como desde la óptica de la victimización, ya que son victimizadas y victimarias. La falta de oportunidades y de poder de las jóvenes de los márgenes y las periferias hace que desarrollen problemas únicos y bien diferenciados.

Los resultados de este estudio contemplan una serie de elementos o factores interrelacionados, imprescindibles para conocer el desarrollo de las trayectorias de vida de las mujeres jóvenes que terminan dentro del sistema de justicia juvenil con una medida de institucionalización. Tales como: comportamiento suicidas o autolesiones, institucionalizaciones o medidas previas, controles formales o informales; así como la socialización con los elementos drogodependencia, encarcelación, delincuencia, consumo de sustancias tóxicas, violencia, prostitución, mendicidad o sinhogarismo, embarazos, abortos y maternidad, faltas, delitos y otros «malos comportamientos de las jóvenes», maltrato dentro del grupo de iguales, de la pareja y la familia, embarazos no deseados, abortos y maternidad, familia multiconflictiva, fuga(s) para ir a convivir con la pareja o casarse; así como estética, victimización, socialización con los roles de género, etnia y clase y cultura y violencia en los centros educativos, entre otros. La mayor parte de las jóvenes del estudio pertenecen a barrios marginales o desestructurados; en segundo lugar aparecen jóvenes de barrios populares o del extrarradio. En menor medida, y dentro de estos barrios se da la tipología de: jóvenes adoptadas, menores no acompañadas, jóvenes que han sufrido un hecho frustrante grave, jóvenes con discapacidad psíquica o social y con enfermedades mentales. Para comprender la amplitud del fenómeno, a continuación se explicará una buena parte de los elementos y factores recogidos anteriormente.

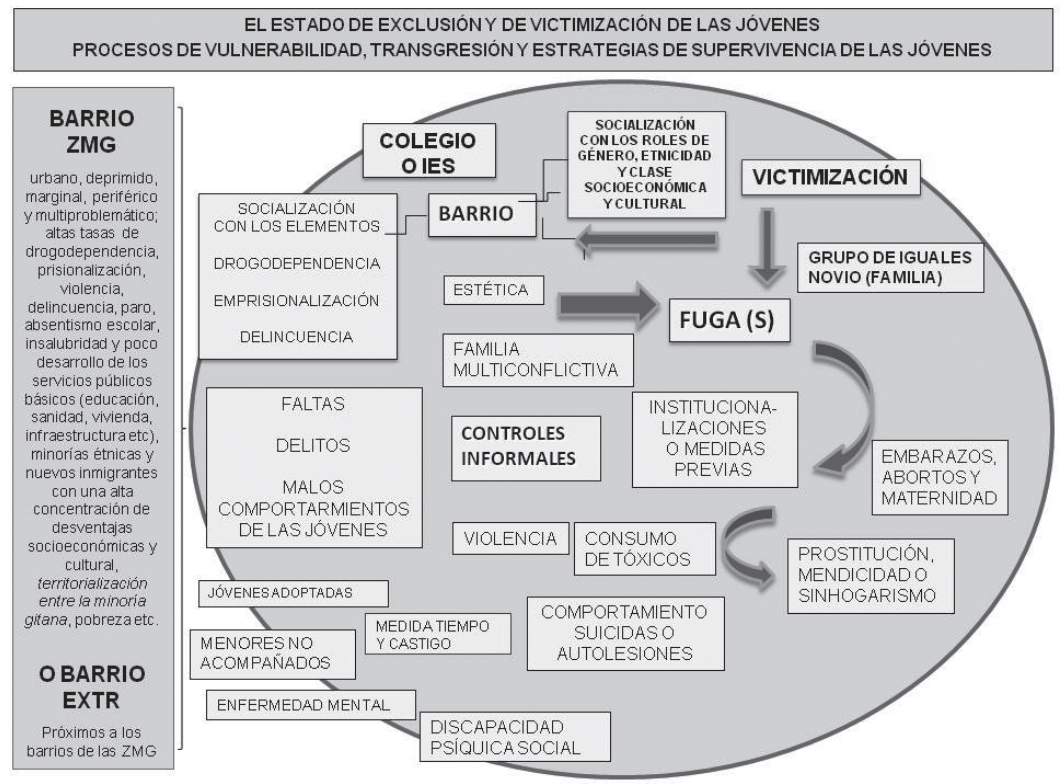

Gráfico 1. 


\subsection{El estado de exclusión y de victimiza- ción de las jóvenes}

3.1.1. El barrio de procedencia de una gran parte de las jóvenes del estudio es marginal, urbano, deprimido, periférico y multiproblemático, con altas tasas de drogodependencia, encarcelación, violencia, delincuencia y tráfico de drogas; así como también con paro, absentismo escolar, insalubridad y poco desarrollo de los servicios públicos básicos -educación, sanidad, vivienda, infraestruc- tura etc.- - y que está integrado por minorías étnicas autóctonas y nuevos inmigrantes con una alta concentración de desventajas socioeconómicas y culturales, pudiéndose hablar de una clara territorialidad de sus habitantes. El delito de las jóvenes está relacionado con los problemas del barrio marginal, es decir: peleas, hurtos, robos, tráfico de drogas etc. (véase Cuadro 1).

La segunda modalidad encontrada es el barrio del extrarradio (EXTR), próximo a las zonas marginales (ZMG), que comparten los pro-

\begin{tabular}{|c|c|c|c|c|c|}
\hline $\begin{array}{l}\text { Zona urbana } \\
\text { o costero-urbana }\end{array}$ & $\begin{array}{l}\text { Tipología } \\
\text { del barrio }\end{array}$ & $\begin{array}{c}\text { Delitos } \\
\text { de las chicas }\end{array}$ & $\begin{array}{l}\text { Tipología } \\
\text { de familia }\end{array}$ & $\begin{array}{l}\text { Quién reporta } \\
\text { la denuncia }\end{array}$ & $\begin{array}{l}\text { Por qué entra } \\
\text { en el centro }\end{array}$ \\
\hline $\begin{array}{l}\text { Barrios margina- } \\
\text { les y excluidos. }\end{array}$ & $\begin{array}{l}\text { Alta conflictivi- } \\
\text { dad. } \\
\text { Tráfico de dro- } \\
\text { gas y armas, } \\
\text { violencia, des- } \\
\text { empleo, exclu- } \\
\text { sión social, alta } \\
\text { concentración de } \\
\text { etnicidad con } \\
\text { desventaja social } \\
\text { y económica, } \\
\text { etc. }\end{array}$ & $\begin{array}{l}\text { Delitos más gra- } \\
\text { ves. } \\
\text { Tráfico de dro- } \\
\text { gas, peleas o } \\
\text { agresiones, hur- } \\
\text { tos, robos, etc. }\end{array}$ & $\begin{array}{l}\text { Muy conflictiva: } \\
\text { alcoholismo, } \\
\text { drogodependen- } \\
\text { cias, toxicoma- } \\
\text { nías, pobreza, } \\
\text { prisionalización, } \\
\text { dependencia de } \\
\text { SSSS o Servi- } \\
\text { cios sociales, ba- } \\
\text { jos recursos eco- } \\
\text { nómicos, } \\
\text { empleos preca- } \\
\text { rios y sexualiza- } \\
\text { dos, etc. }\end{array}$ & $\begin{array}{l}\text { La víctima, la po- } \\
\text { licía. }\end{array}$ & $\begin{array}{l}\text { Incumplimiento } \\
\text { de la Libertad } \\
\text { vigilada o LV; } \\
\text { robo, hurto, trá- } \\
\text { fico de drogas, } \\
\text { violencia, etc. }\end{array}$ \\
\hline $\begin{array}{l}\text { Municipios o ba- } \\
\text { rrios del extra- } \\
\text { rradio (o de cla- } \\
\text { se trabajadora). }\end{array}$ & $\begin{array}{l}\text { Baja o media } \\
\text { conflictividad } \\
\text { (próxima a estas } \\
\text { zonas conflicti- } \\
\text { vas). } \\
\text { No conflictivos. }\end{array}$ & $\begin{array}{l}\text { «Delitos» como } \\
\text { fugarse de casa, } \\
\text { consumo o expe- } \\
\text { rimentación con } \\
\text { drogas, quitar di- } \\
\text { nero en casa, } \\
\text { discutir, tener un } \\
\text { novio o iguales } \\
\text { no aprobados } \\
\text { por la familia, } \\
\text { desobedecer la } \\
\text { autoridad mater- } \\
\text { na, etc. } \\
\text { Rebeldía juvenil } \\
\text { o mal comporta- } \\
\text { miento de las jó- } \\
\text { venes. } \\
\text { Maltrato intrafa- } \\
\text { miliar. }\end{array}$ & $\begin{array}{l}\text { Familias de clase } \\
\text { media trabajado- } \\
\text { ra. } \\
\text { Familias adopti- } \\
\text { vas. } \\
\text { Familias de clase } \\
\text { media en las que } \\
\text { la joven vive un } \\
\text { episodio estre- } \\
\text { sante (malos tra- } \\
\text { tos, abuso se- } \\
\text { xual, etc.). }\end{array}$ & $\begin{array}{l}\text { Agencias de con- } \\
\text { trol, la familia, } \\
\text { SS.SS, el equipo } \\
\text { educativo, etc. }\end{array}$ & $\begin{array}{l}\text { Incumplimiento } \\
\text { de LV (normal- } \\
\text { mente, debido al } \\
\text { maltrato intrafa- } \\
\text { miliar). }\end{array}$ \\
\hline
\end{tabular}

Cuadro 1. Relación entre el barrio y los delitos de los jóvenes.

Fuente: Elaboración propia.

Nota: Parte de las jóvenes adoptadas habrían vivido en su infancia o su niñez en este tipo de barrios. 
blemas del barrio, pero con menor intensidad. Es necesario puntualizar que el delito de violencia o maltrato intrafamiliar se da en jóvenes de las zonas del extrarradio, jóvenes adoptadas y jóvenes que han sufrido un hecho frustrante en su vida, pertenecientes a la clase media en su mayoría.

3.1.2. La victimización, entendida como: maltrato físico, psíquico, emocional, negligencia, abandono, abusos sexuales y bulling, padecida por las jóvenes del estudio, presenta desproporcionadas ratios de negligencia y de abuso. Esta situación se da en todas las jóvenes, aunque de forma más pronunciada en aquellas zonas marginales. Dicha victimización es continua y transversal en su historia de vida y en la familia es un punto de inflexión que da como resultado la fuga (o fugas) puntual, intermitente, definitiva del ámbito familiar, siendo el barrio con sus parques, plazas y calles un elemento importante de socialización, especialmente en las zonas marginales. Es temprana la socialización en sustancias tóxicas, delitos, cárcel, y la convivencia con los conflictos y la violencia intrafamiliar y de pareja, o en el barrio, entre iguales, en los institutos y centros de formación, entre otros. Esta situación es más pronunciada en las zonas marginales; así como la socialización en roles de género, etnia y clase social son elementos imprescindibles para la comprensión del fenómeno.

3.1.3. Los roles de género están influidos por la clase social y la etnia. Por ello las jóvenes del estudio presentan estándares tradicionales. Desde edades muy tempranas desempeñan labores de apoyo, refuerzo y suplantación de roles paternos o maternos, cuando se encuentran ausentes por diferentes motivos, habitualmente por problemas con los sustancias tóxicas, encarcelación entre otros. Así mismo realizan las tareas domésticas, proporcionan cuidados, participan en la economía informal, trabajan legal o ilegalmente, tienen ocupaciones temporales de subsistencia, mal remuneradas, precarias y escasas para las necesidades y siempre prototípicas de género. Sus madres, hermanas y abuelas asumen solas las responsabilidades económicas y del cuidado con respecto a sus hijos e hijas. La pobreza, la exclusión y la soledad envuelven parte de la vida de las jóvenes, espe- cialmente quienes pertenecen a las zonas marginales, y tienen una dependencia total de las ayudas sociales.

En cuanto a la etnicidad es necesario destacar que comparten más las características de grupo excluido que de grupo étnico, con altas tasas de mestizaje entre grupos minoritarios o étnicos con bajo poder socioeconómico. El grupo de gitanas y mestizas es sin duda un grupo muy heterogéneo, encontrándose perfiles de mujeres jóvenes muy diversos que definen o condicionan sus trayectorias de vida e itinerarios de vida delincuenciales.

En este apartado quiero destacar la importancia de los «problemas de las chicas», es decir: abuso sexual, acoso sexual, bulling sexual, embarazo, aborto, maternidad entre otros, que sin duda serán claves para comprender la trayectoria de vida de las jóvenes, y su contacto con el sistema de justicia juvenil.

3.1.4. Las escuelas o los institutos de formación profesional (IES) que frecuentan las jóvenes son públicos y están ubicados en barrios marginales o extrarradios, comparten la problemática de los mismos. Las características que presentan son: asistencia irregular a clase, absentistas, repetición de curso, conductas disruptivas dentro de las escuelas o IES, expulsiones, niveles educativos inferiores a su edad, abandono escolar sin obtener el graduado escolar, etc. En su estructura social y familiar son escasas las personas que han completado el graduado escolar y las ocupaciones que desempeñan son las prototípicas del rol masculino o femenino, afectándoles de forma especial el paro, mercado ilegal, inestable y mal pagado.

3.1.5. En cuanto al grupo de iguales o del novio (s): comparten problemas del barrio y sus espacios sociales (IES, escuelas, recursos sociales, etc.). El estudio sugiere que en primer lugar es relevante el grupo de iguales y posteriormente el papel del novio y su familia. Así mismo asociarse con un grupo de iguales o novios delincuentes o consumidores aumenta el riesgo de delinquir o de consumo de sustancias tóxicas.

3.1.6. Las institucionalizaciones previas actúan como control informal además de constituir un fuerte capital social, al ser en ellas donde 
conocen a sus amistades o novios. Los ingresos en estos centros, en cualquiera de sus modalidades, los motivan las negligencias, los abandonos, desamparos y malos tratos, el sinhogarismo, la mendicidad, el haber cometido delitos o faltas antes de los 14 años o el mal comportamiento, etc. Las fugas temporales o permanentes del hogar: se producen fundamentalmente por la victimización sufrida en su propio hogar. Por lo que el barrio, sus calles, plazas y parques, son escenarios de la socialización en la delincuencia, las toxicomanías, la violencia etc. En esos espacios conocen a sus iguales y a sus parejas, que es más acentuado en el caso de las jóvenes que pertenecen a las zonas marginales. En el estudio se ha visto como las fugas, tanto las definitivas como las esporádicas, son elementos de inflexión y detonantes de otros procesos de vulnerabilidad de la joven.

\subsection{Los procesos de vulnerabilidad y las es- trategias de transgresión de las jóvenes}

3.2.1. Las estrategias de supervivencia que utilizan para afrontar hechos frustrantes son legales, ilegales, alegales, delictivas y casi siempre dentro de contextos marginales, periféricos o de extrarradio. Muchas de estas estrategias o formas de huida dan lugar a nuevos procesos de vulnerabilidad; tales como el consumo o abuso de sustancia tóxicas, los malos tratos de su pareja - sin denuncia formal o informal-, los embarazos tempranos, abortos o la maternidad también temprana. Irse a convivir con una pareja, casarse — «la escapá» gitana- son otro tipo de estrategias comúnmente adoptadas para satisfacer necesidades económicas y afectivas. Esta cuestión se da tanto en las jóvenes procedentes de las zonas marginales como de las del extrarradio. Otra modalidad detectada, pero sólo para las chicas que proceden de las zonas marginales, es irse a la calle o tener que buscarse la vida y ejercer la prostitución, la mendicidad o sinhogarismo $u$ otras situaciones intermedias. El cuerpo ha sido un elemento de análisis interesante, sobre todo para ver las múltiples estrategias de resistencia, control y descontrol en las jóvenes. Muchas de ellas responden a los hechos traumáticos vividos con intentos de suicidio, anorexia, bulimia, autolesiones, consumo de sustancias tóxicas y peleas.
3.2.2. En referencia a los embarazos abortos, maternidad: las jóvenes del estudio no tienen control acerca de cómo prevenir los embarazos no deseados. Cuando se quedan embarazadas ven una oportunidad para fundar una familia o cambiar de estilo de vida. Los embarazos se dan a edades tempranas, antes de los 16 en las zonas marginales y se producen en circunstancias y etapas en que la menor consume, pelea o delinque, y también es maltratada por su pareja o por la familia. Presentaban también unas altas tasas de abortos en situación de riesgo para su salud, como por ejemplo, por ingesta de fármacos o sustancias tóxicas. La maternidad es para estas jóvenes una estrategia afectiva u ocupacional.

\subsubsection{El consumo de sustancias tóxicas se da} tanto en las jóvenes de las zonas marginales y del extrarradio, al haber recurrido muchas de ellas al consumo de sustancias tóxicas debido a los hechos frustrantes de su vida, sobre todo al cannabis, la cocaína, el alcohol y tabaco, las pastillas como tranquimacín y al uso y abuso de psicotrópicos. El policonsumo o el uso de drogas duras es minoritario, pero aparece más pronunciado en las jóvenes que proceden de las zonas marginales, donde también se da este tipo de drogas. Este estudio sugiere que el consumo como "problema» fuerza a las consumidoras a tener conductas delictivas o «malos comportamientos» pero no es necesariamente un punto de inflexión en sus vidas, sino un problema que se añade a su biografía. Además, algunas de las jóvenes reciben un tratamiento psicológico o psiquiátrico no necesariamente por su pasado victimario, sino por el inicio o la sospecha de un posible consumo.

\subsubsection{El maltrato o violencia intrafamiliar es-} tán relacionados con el mal comportamiento en sus casa, es decir con violar la normativa familiar, no acudir a la hora señalada, fugarse de casa, consumir sustancias tóxicas, ausentarse de la escuela, frecuentar el grupo de iguales y a un novio no aprobado por la familia, así como a tener intentos autolíticos o suicidas; así como peleas, enfrentamientos verbales o insultos y físicos, como arañazos, mordeduras, empujones, romper trastos, etc. minoritarios y aislados. Las características que presentan son: enfrentamientos recíprocos, la joven ha sido o es sujeto - espectadora o autora- de una si- 
tuación continuada de malos tratos dentro del hogar; reprocha a su madre por no haberla defendido de pequeña de esos abusos. Los controles informales de los trabajadores y las trabajadoras sociales, docentes, madres o padres o vecinos, informan o denuncian estos comportamientos a la justicia juvenil. En el estudio se ha percibido una cuasi-relación entre haber padecido violencia en el hogar y el delito por maltrato intrafamiliar de las jóvenes. En este apartado están representadas las jóvenes de las zonas del extrarradio, jóvenes adoptadas, jóvenes que han sufrido un hecho frustrante en su vida y que pertenecen a una clase media-baja. Los comportamientos de estas jóvenes se definen o redefinen como faltas o delitos. Habitualmente el juez o la jueza les imponen una medida previa. Las jóvenes la incumplen y son institucionalizadas en el centro de reforma.

El presente trabajo sugiere que la violencia de las jóvenes de las zonas marginales no tiene un uso regular; es decir son situaciones puntuales, pese a que la violencia está en la calle, la familia, el colegio o el Instituto, en el grupo de iguales, en su pareja etc. Presentan cotidianeidad y habituación a hechos o situaciones violentas, y es una estrategia de supervivencia en su hábitat, también violento.

3.2.5. Las faltas o delitos de las jóvenes que las llevan al internamiento fundamentalmente el incumplimiento de una medida previa - como servicios a la comunidad - o al quebrantamiento de la libertad vigilada. Los motivos que han dado lugar a una medida previa son: a) «malos comportamientos de las jóvenes» redefinidos en maltrato(s) intrafamiliar (es). b) Delitos económicos tales como hurtos o robos, fundamentalmente en las jóvenes que proceden de las zonas marginales donde hay una fuerte representación de colectivos con bajos recursos socioeconómicos y culturales. Excepcionalmente, se da el tráfico de drogas, $\mathrm{y}$ en un escenario ampliamente conocido por las autoridades y el resto de la sociedad. El tráfico de drogas es una fuente de ingresos familiares para colectivos con bajas posibilidades de obtenerlos por la vía legal. Algunas chicas que han desarrollado un hábito de consumo comienzan a traficar para pagarse las dosis, pero también para satisfacer las necesidades básicas. En el Cuadro 2 se muestra la relación de las jóvenes del estudio con la victimización y los delitos.

Resulta más que evidente que las jóvenes del estudio cometen más delitos de los que suelen recoger los organismos de justicia juvenil. Muchas de las jóvenes de las zonas marginales que se inician a edad temprana desarrollan itinerarios más delincuenciales. Sin duda, el delito es inherente a su historia de vida o estilo marginal y son quienes más victimización han sufrido en la familia, en el barrio, entre iguales o en la pareja, en el Instituto o en la escuela. Sus delitos son de mayor gravedad - registrados y no registrados-, asumen peor su grado de responsabilidad en el mismo y minimizan su importancia. En cuanto a los robos con fuerza o violencia, normalmente se producen en grupo o en pareja. Su participación en el delito es subsidiaria; es decir, que realizan funciones tales como: quitar los objetos de valor, vigilar, amedrentar, sustraer o encubrir, porque quien tiene un papel más activo en la comisión del delito suele ser normalmente un varón, mayor que ellas. Los delitos más graves contra las personas u homicidios analizados — se constata la necesidad de realizar más investigaciones en este sentido - tienen relación con su rol de género o con los considerados «problemas de las chicas», que se han descrito anteriormente, y dentro de la socialización de «lo marginal». Por último cabe señalar que en todo mi estudio no he encontrado a ninguna joven institucionalizadade clase socioeconómica alta.

\section{Discusiones finales}

El presente artículo anima a realizar nuevos estudios o a profundizar en éste. Además, propone la necesidad de revisar y crear un debate serio sobre el rol de las jóvenes en el sistema de justicia juvenil, ya que las mujeres del estudio sufren múltiples situaciones de marginalidad, no sólo de género, sino también por su pertenencia étnica y de clase socioeconómica.

Es urgente realizar una reflexión sobre la victimización de las jóvenes y su relación con los itinerarios delincuenciales, ya que ha sido constantemente ignorada, al igual que los elementos de exclusión de las jóvenes que les limiten las oportunidades con respecto a los varones o a las otras jóvenes de clase socioeconómica más desahogada. 


\begin{tabular}{|c|c|c|c|}
\hline \multirow[t]{2}{*}{ Jóvenes entrevistadas } & \multirow[t]{2}{*}{ Delito registrado } & $\begin{array}{c}\text { Malos tratos, abuso sexual, } \\
\text { abandono, negligencia } \\
\text { y bulling }\end{array}$ & $\begin{array}{l}\text { Malos tratos, abuso sexual, } \\
\text { abandono y negligencia }\end{array}$ \\
\hline & & Fuera de la familia & En la familia \\
\hline $\begin{array}{l}\text { (EXTR, paya, CIF 5, } \\
18 \text { años) }\end{array}$ & Maltrato intrafamiliar & $\begin{array}{l}16-17 \\
X\end{array}$ & \\
\hline $\begin{array}{l}\text { (EXTR, paya, CIF 3, } \\
18 \text { años) }\end{array}$ & & & \\
\hline $\begin{array}{l}\text { (EXTR, gitana, CIF 15, } \\
15 \text { años) }\end{array}$ & $\begin{array}{l}\text { Incumplimiento liber- } \\
\text { tad vigilada }\end{array}$ & $14-15$ & $\mathrm{X}$ \\
\hline $\begin{array}{l}\text { (EXTR, comunitaria, } \\
\text { CIF 10, } 15 \text { años) }\end{array}$ & $\begin{array}{l}\text { Incumplimiento liber- } \\
\text { tad vigilada, mal com- } \\
\text { portamiento en el cen- } \\
\text { tro anterior }\end{array}$ & $\begin{array}{l}14 \\
X\end{array}$ & $\mathrm{X}$ \\
\hline $\begin{array}{l}\text { (EXTR, paya, CIF 7, } \\
16 \text { años) }\end{array}$ & $\begin{array}{l}\text { Incumplimiento liber- } \\
\text { tad vigilada }\end{array}$ & $\begin{array}{l}16 \\
X\end{array}$ & $\mathrm{X}$ \\
\hline $\begin{array}{l}\text { (EXTR, paya, CIF 6, } \\
19 \text { años) }\end{array}$ & $\begin{array}{l}\text { Incumplimiento liber- } \\
\text { tad vigilada y mal } \\
\text { comportamiento en el } \\
\text { centro }\end{array}$ & 16 & No se dispone de datos \\
\hline $\begin{array}{l}\text { (EXTR, paya, CIF 16, } \\
15 \text { años) }\end{array}$ & $\begin{array}{l}\text { Incumplimiento liber- } \\
\text { tad vigilada }\end{array}$ & $\begin{array}{l}15 \\
X\end{array}$ & $\mathrm{X}$ \\
\hline $\begin{array}{l}\text { (ZMG, mestiza, CIF 1, } \\
19 \text { años) }\end{array}$ & & $\begin{array}{l}8-17 \\
X\end{array}$ & $\mathrm{X}$ \\
\hline $\begin{array}{l}\text { (ZMG, gitana, CIF 8, } \\
16 \text { años) }\end{array}$ & & $\begin{array}{l}8-15 \\
X\end{array}$ & $\mathrm{X}$ \\
\hline $\begin{array}{l}\text { (ZMG, paya, CIF 11, } \\
16 \text { años) }\end{array}$ & $\begin{array}{l}\text { Incumplimiento libertad } \\
\text { vigilada, mal comporta- } \\
\text { miento en el centro }\end{array}$ & $\begin{array}{l}15-16 \\
X\end{array}$ & $\mathrm{X}$ \\
\hline $\begin{array}{l}\text { (ZMG, paya, CIF 14, } \\
15 \text { años) }\end{array}$ & & $\begin{array}{l}11-16 \\
X\end{array}$ & $X$ \\
\hline $\begin{array}{l}\text { (ZMG, mestiza, CIF } \\
12,17 \text { años) }\end{array}$ & & $16-17$ & $\mathrm{X}$ \\
\hline $\begin{array}{l}\text { (ZMG, gitana, CIF 2, } \\
18 \text { años) }\end{array}$ & & $14-16$ & \\
\hline $\begin{array}{l}\text { (ZMG, mestiza CIF 9, } \\
18 \text { años) }\end{array}$ & & $14-17$ & $\mathrm{X}$ \\
\hline $\begin{array}{l}\text { (ZMG, paya, CIF 13, } \\
18 \text { años) }\end{array}$ & $\begin{array}{l}\text { Incumplimiento liber- } \\
\text { tad vigilada }\end{array}$ & $\begin{array}{l}13-17 \\
X\end{array}$ & $\mathrm{X}$ \\
\hline $\begin{array}{l}\text { (ZMG, gitana, CIF 4, } \\
18 \text { años) }\end{array}$ & & $\begin{array}{l}17 \\
X\end{array}$ & $\mathrm{X}$ \\
\hline
\end{tabular}

Cuadro 2. Jóvenes, delitos y pasado victimrio.

Fuente: Elaboración propia (2008). 
También encontramos a jóvenes en los centros de reforma de menores que no han cometido como tal «delito» alguno y que sí han sido victimizadas dentro y fuera de la familia con total impunidad. Habitualmente, se reporta el mal comportamiento de las jóvenes en los controles informales $\mathrm{y}$, posteriormente, derivan en «faltas» por las que, por lo general, aplica el juez una medida de libertad vigilada o de servicios a la comunidad. El incumplimiento de la medida provoca que las jóvenes terminen ingresando en los centros de reforma. Creo que este hecho debería ser cuestionado profundamente, ya que el internamiento se considera la medida última y para casos de delitos graves.

A lo largo del artículo hemos comprobado que no podemos seguir obviando la socialización de las jóvenes en los roles de género desde los márgenes y tampoco la edad y procesos madurativos, la clase socioeconómica o cultural y la etnicidad, en estos contextos se encuentran muchas de las pautas que se vinculan a la delincuencia de estas mujeres. Lo que evidencia el estudio es que no podemos buscar soluciones al respecto, sin tener en cuenta las voces y las experiencias vitales de las chicas en reforma. Ya que según Davidson (1983), las necesidades de las jóvenes que entran en contacto con el sistema de justicia juvenil se relacionan con necesidades fundamentalmente económicas y de supervivencia.

Se hace imprescindible considerar sus trayectorias victimizadas y victimarias; reconsiderar los controles sociales, informales y formales, de las jóvenes en los futuros trabajos científicos y de intervención, así como el trato discriminatorio o no reportado en varios grados y niveles del sistema, incluyendo los arrestos policiales, las decisiones judiciales, las disposiciones y los tratamientos, especialmente el institucional, con objeto de ver cuánto racismo, sexismo y clasismo existe en todo ello; revisar la situación de exclusión social de las jóvenes, especialmente aquellas de las zonas o los barrios deprimidos y todos sus espacios vitales «incluyendo las escuelas», y en particular, a las de las minorías autóctonas y los nuevos inmigrantes que se han ido incorporando a estos «barrios problema»; comprender y aceptar que las jóvenes crecen y viven en mundos diferenciales y, por lo tanto, estudiar los problemas de estas chicas como únicos y diferenciales, en cualquier caso, los programas y los recursos especiales deben contemplar lo cultural o étnico y de género, y no deben ser un medio para controlar a las jóvenes, y como apuntan diversos autores, hay que tener especialmente en cuenta la etnicidad, ya que las jóvenes de color tienen diferente experiencia por su género, pero también diferente experiencia con las instituciones dominantes en la sociedad (Amaro, 1995; Amaro Agular, 1994; La Framboise y Howard Pitney, 1995; Orenstein, 1994). Asimismo también han de contar con ayuda profesionalizada por su sobre-victimización sufrida entre otros. En definitiva, tal y como concluye una de las jóvenes del estudio en su inacabada trayectoria de vida, «Yo no quiero saber nada de mi familia, porque mi familia me ha hecho mucho daño». Por lo que se requerirían más recursos (fundamentalmente, económicos y de supervivencia) para vivir una vida independiente, porque muchas no van a poder volver a sus hogares con sus familias, como apunta Chesney-Lind (1997), en The Female Offender. Girls, Women, and Crime.

\section{Referencias bibliográficas}

Alder, Cristine y Worrall, Anne (eds.) (2004). Girls'Violence: Myths and Realities. Albany: State University of New York Press.

Batchelor, Susan (2007). 'Prove Me the Bam!' Victimisation and Agency in the Lives of Young Women Who Commit Violent Offences. (Tesis doctoral. University of Glasgow).

Batchelor, Susan, Burman, Michael y Brown, John (2001). Discussing violence: it from the girls. Probation Journal, 48(2), 125-134.

Burman, Michael, Batchelor, Susan y Brown, John (2001). Researching Girls and Violence: Facing the Dilemmas of Fieldwork. British Journal of Criminology, 41(3), 443-459.

Campbell, Anne (1981). Girl Delinquents. Oxford: Basil Blackwell.

Campbell, Anne (1990). On the Invisibility of the Female Delinquent Peer Group. Women and Criminal Justice, 2(1), 41-62.

Campbell, Anne (1999). Staying alive: Evolution, culture, and women's intrasexual aggression. Behavioral and Brain Sciences, 22, 203-252. 
Carlen, Pat (1987). Out of care, into custody. En Pat, Carlen y Anne. Worrall (eds.), Gender, Crime and Justice. Milton Keynes: Open University Press.

Carlen, Pat (1988). Women, Crime and Poverty. Milton Keynes: Open University Press.

Castel Robert (noviembre, 1991). Los desafiliados. Precariedad del trabajo y vulnerabilidad relacional. Revista Topía, 3, 28-35.

Chesney-Lind, Meda (Julio, 1974). Juvenile Delinquency and the Sexualisation of Female Crime. Psychology Today, 4-7.

Chesney-Lind, Meda (1989).'Girls' crime and woman's place: Toward a feminist model of female delinquency. Crime and Delinquency, 35, 5-30.

Chesney-Lind, Meda y Eliason, M (2006). From invisible to incorrigible: The demonization of marginalized women and girls. Crime, Media, Culture, 2, 29.

Chesney-Lind, Meda y Pasko, Laura (2004). The Female Offender: Girls, Women, and Crime. (2 edición). Thousand Oaks, CA: Sage.

Gillborn, D. (1998).Racism, selection, poverty and parents: New Labour, old problems? Journal of Education Policy, 13(6), 717-735.

Heidensohn, Francis (2000). Sexual Politics and Social Control. Buckingham: Open University Press.

McIvor, Guill (ed.) (2004). Women Who Offend. Londres: Jessica Kingsley.

O'Neill, T. (2005).Girls in trouble in the child welfare and criminal justice system. En G. Lloyd (ed.). Problem Girls: Understanding and Supporting Troubled and Troublesome Girls and Young Women. Abingdon: Routledge Falmer. USA

Zahn, Margaret A.(2009). The Delinquent Girl?. Filadelfia: Temple University Press. 


\begin{tabular}{|c|c|c|c|c|c|c|}
\hline Etiquetas & $\begin{array}{c}\text { Edad en el momento } \\
\text { de hacer la entrevista }\end{array}$ & Módulos & $\begin{array}{c}\text { Número } \\
\text { de entrevistas }\end{array}$ & $\begin{array}{c}\text { Lugar } \\
\text { de las entrevistas }\end{array}$ & $\begin{array}{l}\text { Fecha de realización } \\
\text { de las entrevistas } \\
\text { (junio, 2008) }\end{array}$ & $\begin{array}{c}\text { Otro material } \\
\text { visto o analizado }\end{array}$ \\
\hline CIF 1 & 19 & Retroceso & 3 & Sala de visitas & 4,5 y 6 & $\begin{array}{l}\text { Cartas de su novio. } \\
\text { Revisión del } \\
\text { expediente personal }\end{array}$ \\
\hline CIF 2 & 18 & Finalista & 2 & Taller del módulo & 5 y 6 & Carta por escrito \\
\hline CIF 3 & 18 & Finalista & 3 & $\begin{array}{l}\text { En el salón-comedor } \\
\text { del módulo y la } \\
\text { habitación de la } \\
\text { chica las dos últimas }\end{array}$ & 5 y 6,15 & $\begin{array}{l}\text { Fotos. Carta por } \\
\quad \text { escrito }\end{array}$ \\
\hline CIF 4 & 18 & Finalista & 2 & $\begin{array}{l}\text { En el taller del } \\
\text { módulo y en la } \\
\text { habitación de la chica }\end{array}$ & 6 y 7 & Fotos y sentencia \\
\hline CIF 5 & 18 & Finalista & 1 & En su habitación & 7 y 25 & $\begin{array}{l}\text { Fotos. Carta por } \\
\quad \text { escrito }\end{array}$ \\
\hline CIF 6 & 19 & Retroceso & 2 & En su habitación & 15 (mañana y tarde) & $\begin{array}{l}\text { No tienen nada en la } \\
\text { habitación. Revisión } \\
\text { del expediente } \\
\text { personal }\end{array}$ \\
\hline CIF 7 & 16 & Finalista & 2 & $\begin{array}{l}\text { En el taller y en su } \\
\text { habitación }\end{array}$ & 16 y 17 & $\begin{array}{c}\text { Fotos, pósters y } \\
\text { estampas religiosas } \\
\text { de vírgenes y } \\
\text { cristos. Revisión del } \\
\text { expediente personal }\end{array}$ \\
\hline CIF 8 & 16 & Finalista & 2 & En el taller & 17 y 18 & $\begin{array}{l}\text { Me enseña las fotos } \\
\text { y me hace un dibujo } \\
\text { en talleres. Revisión } \\
\text { del expediente } \\
\text { personal }\end{array}$ \\
\hline CIF 9 & 18 & Finalista & 2 & En el taller & 18 y 20 & $\begin{array}{c}\text { Revisión del } \\
\text { expediente personal }\end{array}$ \\
\hline CIF 10 & 15 & Observación & 2 & En su habitación & 18 & $\begin{array}{l}\text { Foto de sus dos } \\
\text { hermanos. Revisión } \\
\text { del expediente } \\
\text { personal }\end{array}$ \\
\hline CIF 11 & 16 & Desarrollo 1 & 1 & En su habitación & 19 & Fotos \\
\hline CIF 12 & 17 & Desarrollo 1 & 1 & En su habitación & 23 & $\begin{array}{l}\text { Fotos. Revisión del } \\
\text { expediente personal }\end{array}$ \\
\hline CIF 13 & 18 & Retroceso & 2 & En su habitación & 23 у 24 & $\begin{array}{c}\text { Revisión del } \\
\text { expediente personal }\end{array}$ \\
\hline CIF 14 & 16 & Desarrollo 2 & 2 & En una sala taller & 24 у 25 & $\begin{array}{l}\text { Fotos. Revisión del } \\
\text { expediente personal }\end{array}$ \\
\hline CIF 15 & 15 & Desarrollo 2 & 1 & En una sala taller & 25 & Fotos \\
\hline CIF 16 & 15 & Observación & 1 & En su habitación & 24 & $\begin{array}{c}\text { Fotos y cartas y } \\
\text { dibujos }\end{array}$ \\
\hline
\end{tabular}

Anexo 1. Entrevistas sociobiográficas realizadas, en junio del 2008.

Fuente: Elaboración propia a partir del trabajo empírico realizado (2008). 